\title{
COVID-19: A Vaccine Priority Index Mapping Tool for Rapidly Assessing Priority Populations in North Carolina
}

\author{
Gregory D. Kearney, DrPH ${ }^{1 *}$, Katherine Jones, $\mathrm{PhD}^{1}$, Yoo Min Park, PhD², Rob Howard, $\mathrm{MS}^{2}$, \\ Ray Hylock, PhD ${ }^{3}$, Bennett Wall, MBA ${ }^{4}$, Maria Clay, PhD ${ }^{5}$, Peter Schmidt, PhD ${ }^{6}$, John Silvernail, \\ $\mathrm{MD}, \mathrm{MPH}^{7}$ \\ ${ }^{1}$ Department of Public Health, Brody School of Medicine at East Carolina University, ${ }^{2}$ Department of \\ Geography, Planning and Environment, East Carolina University, ${ }^{3}$ Department of Health Services \& \\ Information Management, East Carolina University, ${ }^{4}$ Vidant Health, Integrated Care, ${ }^{5}$ Department of \\ Bioethics \& Interdisciplinary Studies, Brody School of Medicine at East Carolina University, ${ }^{6}$ Department \\ of Neurology, Grossman School of Medicine, New York University, ${ }^{7}$ Pitt County Health Department
}

\begin{abstract}
Background: The initial limited supply of COVID-19 vaccine in the U.S. presented significant allocation, distribution, and delivery challenges. Information that can assist health officials, hospital administrators and other decision makers with readily identifying who and where to target vaccine resources and efforts can improve public health response.

Objective: The objective of this project was to develop a publicly available geographical information system (GIS) web mapping tool that would assist North Carolina health officials readily identify highrisk, high priority population groups and facilities in the immunization decision making process.

Methods: Publicly available data were used to identify 14 key health and socio-demographic variables and 5 differing themes (social and economic status; minority status and language; housing situation; at risk population; and health status). Vaccine priority population index (VPI) scores were created by calculating a percentile rank for each variable over each N.C. Census tract. All Census tracts $(\mathrm{N}=2,195)$ values were ranked from lowest to highest (0.0 to 1.0) with a non-zero population and mapped using ArcGIS.
\end{abstract}

Results: The VPI tool was made publicly available (https://enchealth.org/) during the pandemic to readily assist with identifying high risk population priority areas in N.C. for the planning, distribution, and delivery of COVID-19 vaccine.

Discussion: While health officials may have benefitted by using the VPI tool during the pandemic, a more formal evaluation process is needed to fully assess its usefulness, functionality, and limitations.

Conclusion: When considering COVID-19 immunization efforts, the VPI tool can serve as an added component in the decision-making process.

Keywords: Informatics, COVID-19, public health, spatial, vaccine

Abbreviations: Vaccine Priority Index (VPI)

Correspondence: KearneyG@ecu.edu* 
DOI: 10.5210/ojphi.v13i3.11617

Copyright @2021 the author(s)

This is an Open Access article. Authors own copyright of their articles appearing in the Online Journal of Public Health Informatics. Readers may copy articles without permission of the copyright owner(s), as long as the author and OJPHI are acknowledged in the copy and the copy is used for educational, not-for-profit purposes.

\section{Introduction}

On February 9, 2021, the Centers for Disease Control and Prevention reported nearly 27 million cases and 464,000 deaths related to COVID-19 in the U.S.[1] As vaccine supply became increasingly more available, the initial deployment of phased vaccine roll-out plans across the U.S. brought about significant challenges. According to one report, the vaccine shortage saw many states diverging from CDC guidance, operating on different timelines and prioritizing different groups, and were increasingly dependent on where a person lived.[2] Other news reports described the slow roll-out and allocation of COVID-19 vaccine as chaotic and marred by logistical inconsistencies, with varying strategies and disproportionate socioeconomic power structures.[35]

Without question, the COVID-19 pandemic crisis created new and unprecedented challenges. Amid the rush to mass immunize the public with limited vaccine supplies, critical strategic planning and evaluation efforts were needed a priori to ensure efficient and equitable distribution of vaccine to high-risk, priority populations. For example, older adults living in isolated rural areas struggled with low vaccine allocation and transportation barriers. [6]

The ability for health officials to identify high risk populations and facilities in advance, could assist in planning efforts, including improving supply chain delivery, providing accurate estimates of doses to safeguard communities. This paper describes the North Carolina, Vaccine Priority Index (VPI) mapping tool developed by researchers and partners at East Carolina University and Vidant Medical Center. This product was developed during the pandemic as an attempt to assist busy health officials and hospitals in the vaccine decision making process.

\section{Prioritizing Vaccine Distribution}

In September 2020, the National Academies of Sciences and Medicine released the Preliminary Framework for Equitable Allocation of COVID-19 Vaccine. [7] As described in the report, the committee recognized that when available, the allocation of initial supply of COVID-19 vaccine would be tightly constrained. Furthermore, setting priorities for the equitable allocation of vaccine were admittingly challenging given the differing risk and exposure factors by varying population and occupational groups. It was further noted that assigning priority at an individual level posed considerable constraints and were impractical for delivering vaccine. [7] 


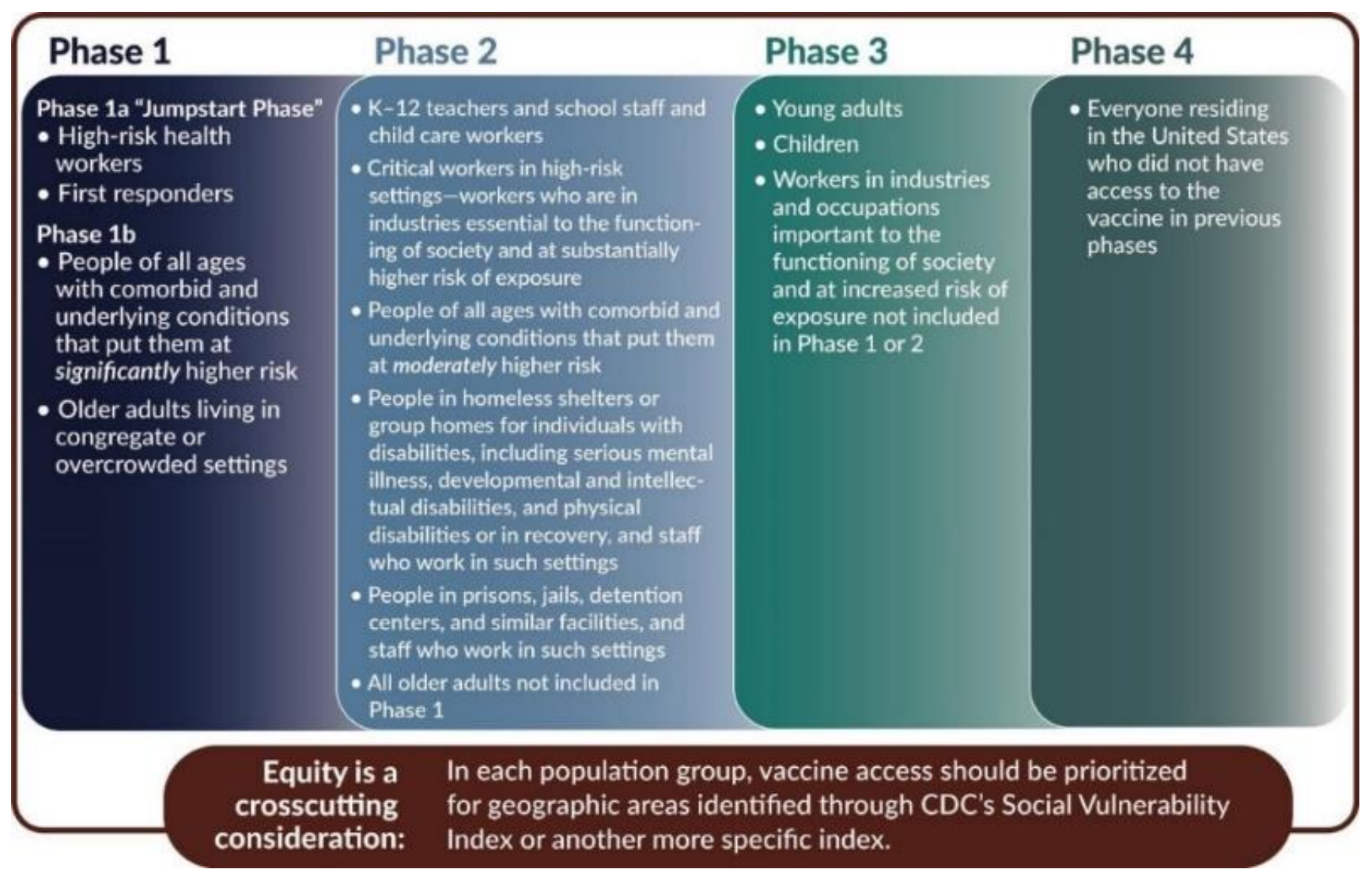

Figure 1. National Academies of Science and Medicine - Phased Approach to Vaccine Access. [7]

Considering the many factors associated with the allocation of vaccine, the committee operationalized risk criteria by characterizing populations and occupational groups based largely on risk and ability of vaccine to mitigate those risks. Using the best available evidence, the committee recommended a four "phased," successive approach for COVID-19 vaccine allocation (Figure 1). In Phase 1 (highest priority), high risk workers in healthcare facilities, first responders, people with significant comorbid conditions and older adults in congregate or overcrowded conditions/settings would receive the initial doses of vaccine.

As noted, "equity" was included as a "cross-cutting consideration" as part of the phased allocation process for vaccine access. To assist with identifying geographical areas for prioritization, the Centers for Disease Control and Prevention (CDC), Social Vulnerability Index (SVI) was suggested. In brief, the SVI is a standardized, data driven system, vulnerability mapping application tool developed primarily to assist emergency disaster management personnel with identifying geographic areas of economic loss, providing social services and public assistance following natural disasters. [8] 


\section{Approach to Vulnerability Mapping}

While the decision to allocate vaccine based solely on population density is one approach for helping communities reach herd immunity, it is flawed by taking into account inherent differences in risks and vulnerability experienced by different individuals and population groups. [9] By identifying where high-risk, vulnerable populations are located, health officials, hospital administrators and other decision-makers can better plan where to target vaccine delivery and intervention strategies.

The social, economic, and health geographics of North Carolina varies considerably across the state; regions, counties, and census tracts differ in population density, urban and rural status, income, race, ethnicity, and health status. Likewise, COVID-19 morbidity and mortality rates differ widely. Some geographic regions have more vulnerable populations including the medically fragile and elderly. Other high-risk groups including frontline health workers, first responders, and workers in occupations deemed "essential" tend to congregate near facilities where they work. While some individuals have resources to help them cope with the virus, others may not. For example, low-wage workers often lack health insurance, do not have transportation to get tested, or go to work when they are ill because they cannot afford to miss work. Such challenges pose considerable exposure risk to COVID-19 for individuals and their co-workers, families, and others in their communities. These low socio-economic factors are key drivers of a person's susceptibility to contracting the virus and managing their sickness once they become ill. Given these limitations, a model of prioritization, allocation, and distribution model for COVID-19, based solely on population density has inherent limitations in reducing the spread.

The aforementioned CDC, SVI method is one approach to consider when prioritizing population vulnerability primarily attributed to the community where they reside.[8] The SVI was designed to standardize a measure of socio-economic status and vulnerabilities at the geographical census tract level. The index has been used extensively in the application for identifying population vulnerability with natural disasters. [10-13] While the SVI continues to prove useful for mapping vulnerability, it was not designed with considerations of risk factors associated with an infectious agent. As COVID-19 spreads, health decision-makers need to have the ability to quickly identify geographic areas that include high-risk facilities and populations so that resources can be allocated and deployed to protect public.

\section{A Vaccine Priority Index for N.C.}

On October 16, 2020, the State of North Carolina released its COVID-19 Vaccination Plan and prioritized critical population groups that would receive the vaccine.[14] Using guidance from the NAM recommendations, it identified a "phased approach" that included high risk health workers, staff in long term care, people over 65 and staff of congregate living settings (i.e., migrant farm camps, jails, prisons, homeless shelters, and anyone with two or more chronic conditions identified by CDC to be high risk for COVID-19 complications).

With the COVID-19 pandemic in full swing, researchers from East Carolina University and Vidant Medical Center worked rapidly to create a website and develop an online, publicly available geospatial web mapping tool. Our goal was to assist health officials, hospital administrators and other decision makers identify and target priority populations and high-risk facilities. Phases 1a and 
Phase $1 \mathrm{~b}$ of the N.C., Vaccine Prioritization Index (VPI) is similar to the NAM priority phased, framework. For this initial approach we focused our efforts on Phases 1a and 1b.

The purpose of this project was to develop a publicly available, online mapping tool that could assist decision makers quickly identify geographical areas of "high-risk, high priority" populations in Phases 1a and $1 \mathrm{~b}$ in the vaccination roll out plan in N.C. In pandemic situations where the need to identify locations and population characteristics are critical for mass vaccinations, this type of applied spatial method offers critical insight for planning, distribution, and delivery of targeted mitigation strategies.

\section{Methods}

\section{Data, Themes and Variables}

The Vaccine Priority Index is composed of 14 variables that describe risk and vulnerability relative to the COVID-19 virus; the 14 variables are grouped into 5 themes (Table 1). The themes are, 1) socioeconomic status, 2) minority status and language, 3) at-risk populations, 4) housing, and 5) health status. The variables within each of the themes were selected based on a combination of factors including population risk and vulnerability relative to the COVID-19 virus, other vulnerability mapping tools, and a review of the literature. This project was reviewed and approved by East Carolina University, Institutional Review Board (UMCIRB\# 20-001299).

The VPI is modeled on the Social Vulnerability Index. The VPI borrows some variables from the SVI, but also adjusts for incorporated risk and vulnerability data pertinent to the COVID-19 pandemic. The VPI also uses a similar ranking methodology to the SVI to assign sub-index values to each census tract based on individual variables. Sub-index values are then combined to create "themes" and the themes are combined to create an overall priority index. The data for four of the themes and eleven of the variables were derived from U.S. Census data (American Community Survey 5-year data, 2014-2018). Data for the remaining theme (health status) and three variables were obtained from the CDC, Diabetes Atlas and the Center for Medicare and Medicaid Services Chronic Conditions Data Warehouse. [15,16] 
Table 1. Themes and associated variables for constructing the Vaccine Priority Index

\begin{tabular}{|c|c|c|c|c|}
\hline \multicolumn{5}{|c|}{ Themes } \\
\hline $\begin{array}{l}\text { Socioeconomic } \\
\text { Status }\end{array}$ & $\begin{array}{l}\text { Minority Status } \\
\text { \& Language }\end{array}$ & $\begin{array}{l}\text { Special-At-Risk } \\
\text { Population }\end{array}$ & Housing & Health Status \\
\hline & & Selected Variables & & \\
\hline $\begin{array}{l}\% \text { below poverty } \\
\% \text { unemployed } \\
\text { Average per capita } \\
\text { income } \\
\% \text { no high school } \\
\text { diploma }\end{array}$ & $\begin{array}{l}\text { \% minority } \\
\% \text { that speak } \\
\text { English "less } \\
\text { than well" }\end{array}$ & $\begin{array}{l}\% \text { age } 65 \text { or older } \\
\% \text { of population } \\
\text { who list } \\
\text { occupation in } \\
\text { high-risk group }\end{array}$ & $\begin{array}{l}\% \text { of households } \\
\text { crowded } \\
\% \text { of people who } \\
\text { live in group } \\
\text { quarters } \\
\% \text { of housing that } \\
\text { is multi-unit }\end{array}$ & $\begin{array}{l}\% \text { of adults who } \\
\text { have diabetes } \\
\% \text { of adults who } \\
\text { are obese } \\
\% \text { of Medicare } \\
\text { beneficiaries } \\
\text { age } 65 \text { or older } \\
\text { who have } 2 \text { or } \\
\text { more chronic } \\
\text { health } \\
\text { conditions }\end{array}$ \\
\hline
\end{tabular}

\section{Rationale for Themes and Variables}

\section{Theme 1, Social and Economic Status.}

Theme 1 combines percent below poverty, percent unemployed, percent without a high school diploma, and average per capita income in a census tract to create a theme to assess socio-economic status. It has been well established that individuals with fewer economic resources are less resilient when responding to disasters, and it is intuitive that this would also be true in a pandemic. This theme contains the same variables as the SVI and is calculated in a similar fashion, except the census tracts are ranked only for the state of North Carolina instead of the entire U.S.

\section{Theme 2, Minority Status and Language.}

Theme 2 combines percent of the tract that is minority (non-white, or Hispanic) and the percent that speak English "less than well." In general, minority populations are at high risk of infectious diseases, particularly when living in multi-generational households and spatially concentrated in neighborhoods. [17,18] Immigrants for whom English is not their native language are also disadvantaged when considering access to health care, testing, and vaccines. [19,20,21] This theme contains the same variables as the SVI and is calculated similarly, but only includes North Carolina and not the entire U.S. census tracts.

Theme 3: Special-At-Risk Populations (also are those prioritized in Phase 1).

Theme 3 combines the percent of the population that is age 65 and over and the percent of the population whose occupations are healthcare or first responder. Increased age is a risk factor for becoming ill from COVID19, and, for those who do become ill, for getting seriously ill or dying. 
Therefore, census tracts with a higher percent of individuals over age 65 are ranked higher priority for vaccine prioritization.

Certain occupations (e.g., healthcare) are also at higher risk for contracting COVID-19 because of close contact with COVID-positive individuals or because the worker is in an occupation where social distancing may not be possible (e.g., first responders). Using Census data, we calculated a percent of the total population in each census tract for occupational groups corresponding with healthcare workers and first responders. For healthcare workers, we combined healthcare practitioners, healthcare technical occupations, and healthcare support occupations.

Healthcare practitioners included physicians of all specialties, physician assistants, nurses, and dentists. Healthcare technical occupations includes licensed practical nurses, EMTs, and health equipment technicians, including respiratory technicians. Healthcare support occupations includes home health aides, nursing assistants, and cleaners and orderlies in a health care setting.

The protective service occupation category was used for first responders and includes law enforcement, firefighters, and correctional service workers. The numbers for each of these groups were summed to create a total number of frontline workers for each census tract, and then the percent of the population was calculated. A census tract with a higher percent is deemed to be at a higher risk, and thus requires a higher priority for the vaccine.

\section{Theme 4: Housing.}

As a highly contagious virus, COVID-19 transmission can occur in social settings, such as in congregate living, close work environments, and/or social occasions such as church services, weddings, funerals, restaurants, and bars. The home is an important transmission environment and one where many people are not able to socially distance from one another. The housing theme combines three Census variables that describes features of the home and living situation that may increase risk for COVID-19, primarily due to the closeness of the setting, proximity to others, and the inability of individuals to socially-distance.

The first variable in the housing theme is multi-unit housing. This variable assesses settings such as apartment buildings, where people are sharing hallways, elevators, and mail stations. The variable measures the percent of housing units in a census tract that are part of a structure that contains 10 or more units. The second variable in the housing theme is crowded housing. Housing units (rental or owner occupied, house or apartment) with more than 1 person per room are considered crowded. The variable assesses the number of housing units in a census tract that are crowded, as a percent of all housing units in the census tract. Note, this measures persons per all rooms in the housing unit, not bedrooms. The third variable for the housing theme is the percent of individuals in the census tract who live in group quarters (institutional settings) such as, nursing homes, assisted living, college dorms, psychiatric hospitals or other long-term healthcare institutional settings, and correctional facilities. Such congregate living arrangements have emerged as one of the riskiest settings for the spread of COVID-19, and numerous outbreaks have been tied to these settings. The group quarters variable measures the number of persons in the census tract that live in such a setting, as a percent of all people in the tract. Where the percent is higher, there is a higher level of vulnerability. 


\section{Theme 5: Health Status.}

It is widely recognized that individuals with certain underlying health conditions are at significantly higher risk of severe COVID-19 illness, or death. While the exact reasons and extent of this are not fully understood, the course of the pandemic thus far has demonstrated that individuals with diabetes, heart disease, kidney disease, COPD, obesity, and immune compromised individuals are all at risk for more severe illness and death if they contract COVID19. Individuals with 2 or more of these or other serious health conditions are at an especially elevated risk. The VPI Health Status theme combines county-level data on the prevalence of diabetes, obesity, and chronic illness. We use county-level data because census tract level health status data is not readily available; the county value is assigned to each census tract within the county. Three variables are combined for this theme.

The first two variables for health status are the percent of adults in the county with diabetes and the percent who are obese. This data was obtained from the CDC, Online Diabetes Atlas, which is a subset of the CDC, Behavioral Risk Factor Surveillance System (BRFSS).[15,22] The BRFSS is an annual health telephone survey conducted by states but standardized at the national level. These two health conditions (diabetes and obesity) are both important co-morbidity risk factors for COVID-19, and this data provides a uniform, reliable estimate for health status at the county level.

The third variable in the health status theme is the percent of Medicare beneficiaries in the county over age 65 who have two or more chronic health conditions. The data was obtained from the Center for Medicare and Medicaid Services Chronic Conditions Data Warehouse [16] and defines an individual as having a chronic condition if persons had a claim for a service or treatment related to that condition within the previous year. It was selected to be included as a measure of population health as it provides a good, general estimate for health status at the county level. Good quality health status data is scarce at the county level, so this data set was chosen for its availability, reliability, and consistency.

\section{VP Index Method}

To construct the VP Index score for Phase 1, source data from Table 1 were compiled and scores were calculated by ranking all census tracts in North Carolina with a non-zero population $(\mathrm{N}=2193)$ from low to high based on the individual variable. A census tract with a low percent in poverty is presumed to have lower vulnerability (and lower vaccine priority), while a tract with a high percent in poverty has a higher vulnerability (and a higher vaccine priority). One exception was income, which was inversely ranked high to low, since tracts with a higher income are presumed to have lower vulnerability, and lower income is presumed to have higher vulnerability.

Once ordered by low to high, each census tract was assigned a rank. The rank number was then used to create an index value. The index value is the rank number divided by the total number of tracts for that variable. The VPI was calculated using the formula,

$$
\text { Vaccine Priority Index }=(\operatorname{rank}-1) / n-1
$$


Census tracts with no population, or a zero value for the variable being ranked (no individuals in poverty live in that tract, for instance) were not assigned a rank, and received a zero value for that index. To calculate themes, indices for individual variables were summed together, and then the summed values re-ordered, low to high. A new rank was assigned for the summed value, and a new, combined index value calculated, using the same method. To calculate the overall VP index, the 5 theme indices were summed and re-ranked, and their rank number used to calculate the final index. The VP Index ranges from 0 to 1 . Lower values indicate lower vulnerability, and lower priority for the vaccine, while higher values indicate higher vulnerability, and higher priority for the vaccine.

\section{Application Features}

Word-Press was used as the operating platform to build a host website to display the VPI (https://enchealth.org/). The website included COVID-19 related dashboard visualizations and ArcGIS Online (ESRI) mapping tool (Figure 2). Users that access the VPI through the website can navigate the mapping visualizations and view the numeric index values and estimated number and percent of high priority vaccine groups identified in Phase 1A and Phase 1B counties and census tracts.

As shown in Figure 3, a mouse-over a geographic area over the map will display a pop-up menu that provides an estimated count of high priority individuals in each county and Census tract. The user can also turn the map layers "on or off" on the right-hand panel to display the VPI or the CDC's Social Vulnerability Index (SVI). By zooming in, key point locations, such as nursing homes, pharmacies, or health clinics are displayed.

Using the filter panel on the left-hand side of the map, the Vaccine Priority Index Category filter and pick the "High" category. The map filters to show only those Census tracts in the highest priority group. Displays of the SVI and VPI are both available at state, county, and census tract levels. The filters can also be used to filter geographic areas based on VPI categories or by the number of priority Phases 1A and 1B groups including percent of healthcare workers, first responders, residents in nursing homes, assisted living facilities, and individuals with chronic health conditions.

Other features including map layers (e.g., imagery, streets, community maps), and individual facilities including the locations of health departments, hospitals nursing homes, meat processing facilities, correctional institutions and pharmacies) with address and information related to each facility are also viewable. 


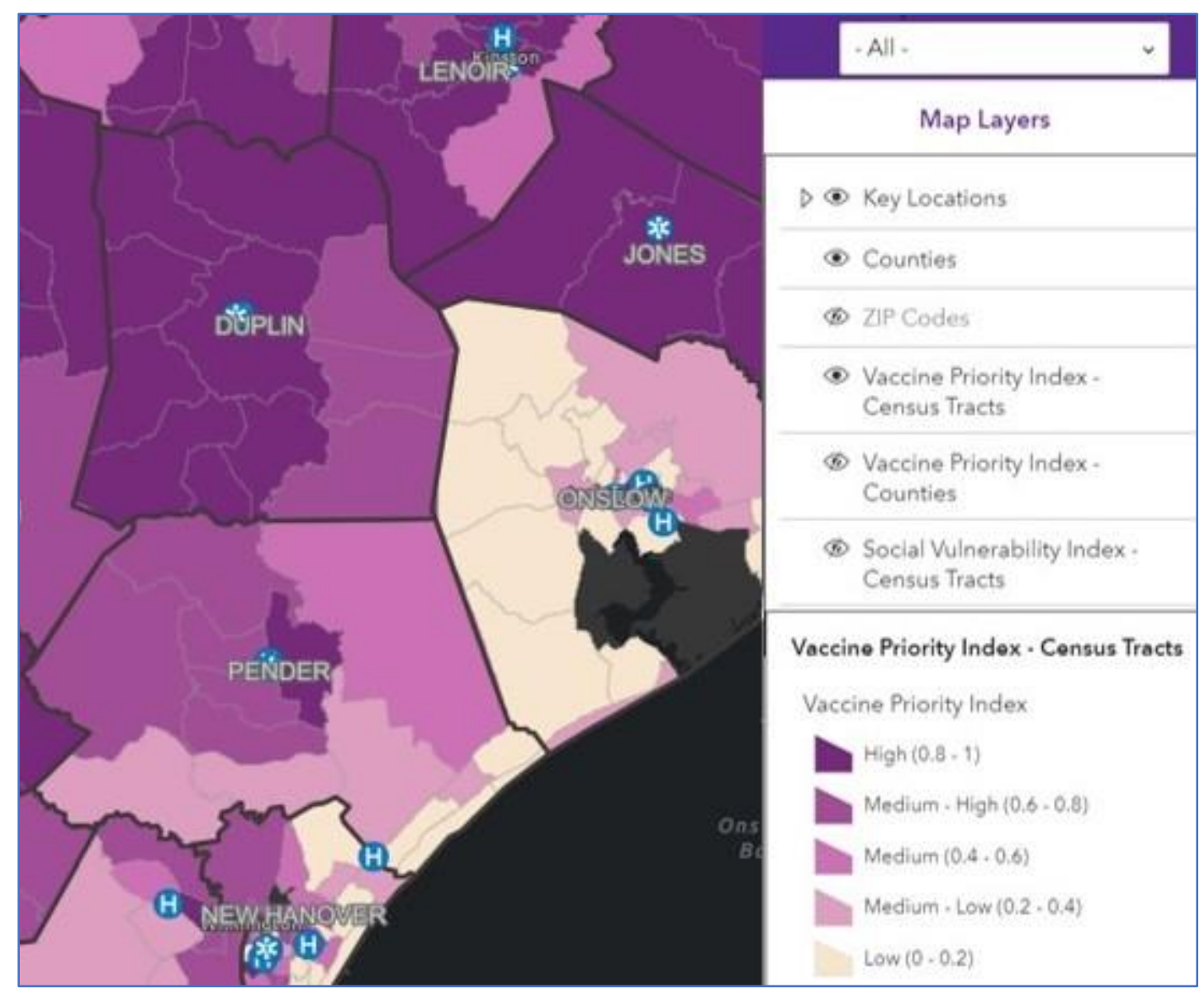

Figure 2. Eastern North Carolina (ENC Health) Vaccine Priority Index (https://enchealth.org/) 


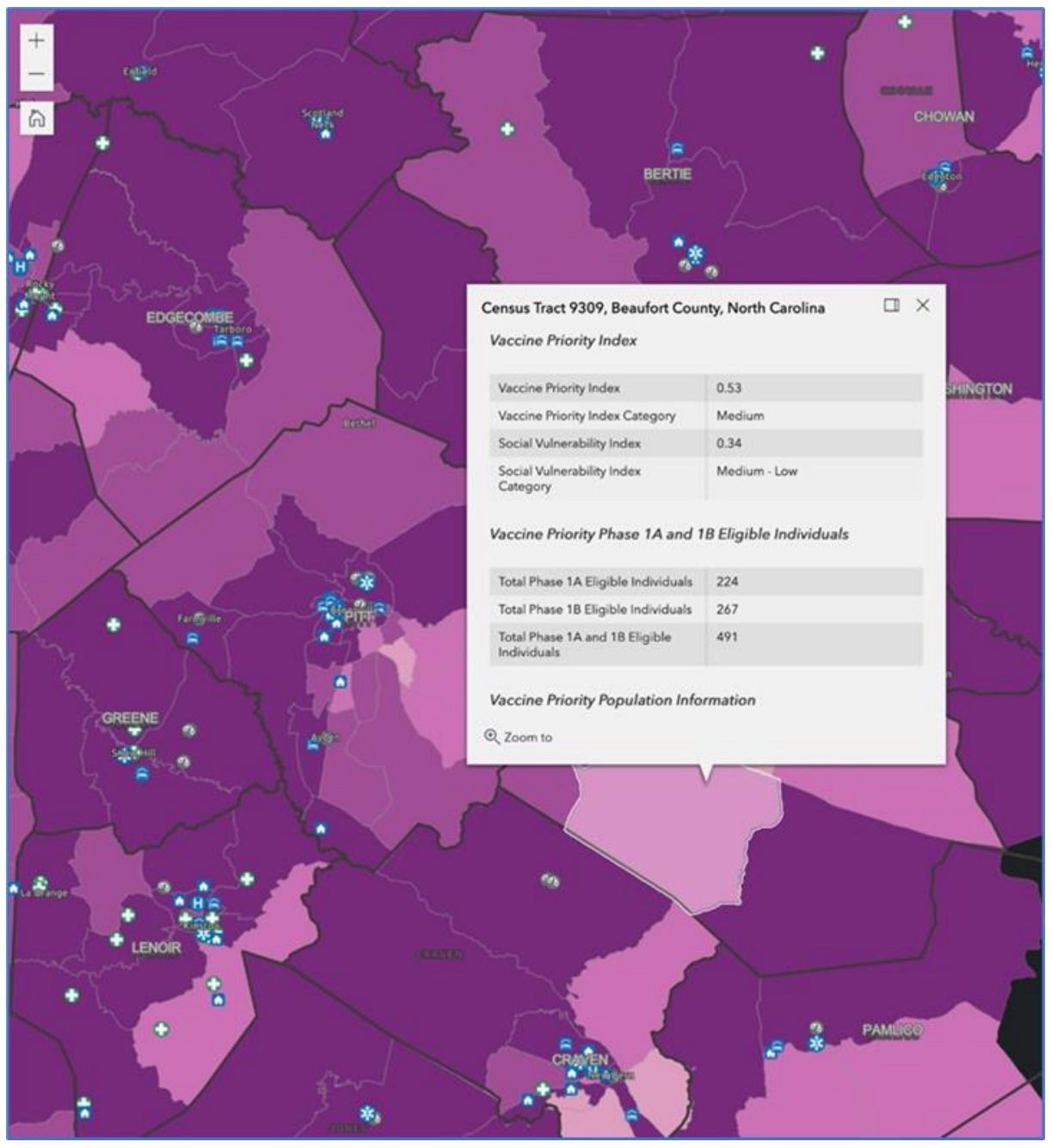

Figure 3. Vaccine Priority Index Mapping Tool (https://enchealth.org/)

\section{Discussion}

The VPI was created in rapid response to the COVID-19 pandemic and the need to provide health officials decision makers with added information for quickly identifying high risk populations and facilities for vaccine delivery. The advantages and challenges of the VPI are listed below.

- Efficient - the VPI translates priority groups (e.g., NAM recommended Phase 1A and Phase 1B priority groups) into a ranked index value to quickly determine where vulnerable groups are located.

- Rapid Visualization - key point locations of high-risk, key facilities including hospitals, nursing and assisted living homes, meat packing facilities, FQHC's, pharmacies, correctional institutions and health departments can readily be found. Additional base map layer features including roads and other imagery can be added to maps. As new location centers emerge (e.g., large vaccination sites or drive through sites) can easily be incorporated into the model. 
- Vaccine Delivery - while the data is derived from the US Census and other publicly derived, national datasets, it is only a metric or a guide to assist with the vaccine delivery and distribution process.

\section{Strengths and Limitations}

The timing of the release of the VPI tool to N.C. health departments was critically important to it's success and came at a time when vaccine plans for $\mathrm{NC}$ were initially being rolled out. Our efforts to promote the tool's usefulness and abilities to health officials and hospital administrators gained positive attention. However, given the overwhelming duties and responsibilities of healthcare workers and providers to the pandemic, our ability to gain feedback was somewhat limited. Nevertheless, future plans include distributing formal surveys to health departments and others to gain additional insight so that modifications can be made accordingly. Also, at the onset of this project, our VPI tool was unique, and there were few other mapping tools available. However, as time progressed, an increase in commercial and non-commercial mapping tools have become publicly available. Many of the newer products display features with varying features, and capable of conducting advanced statistical analysis. Nevertheless, the VPI remains unique to N.C. The data for the VPI were derived primarily from the U.S. Census and health surveys. While we used the most current data sets for this project, changing population composition and people not necessarily living where they work, or play presents inherent limitations. [8]

\section{Recommendations and Conclusions}

COVID-19 remains a highly communicable, infectious agent that threatens the health and safety of society. At the time of this writing, mass vaccination campaigns have occurred throughout the U.S. As COVID-19 case and death rates show an overall downward trend, new variant strains continue to emerge, questioning the return to normal operations. Other challenges such as hesitancy, access to care, conspiracy theories and other reasons contribute to an average of only 59.4\% of adult Americans having been fully vaccinated. [23] Despite these challenges, public health and healthcare workers continue to remain vigilant in its prevention, intervention, and treatment efforts. The VPI tool can be considered a viable option for assisting decision makers with identifying high risk populations and areas to target to protect North Carolina communities.

\section{Acknowledgements}

Thanks to support from people that assisted with the development of this project including the Dartmouth Atlas Project, ESRI, Dr. Keith Keene and Cheryl Walters Denny at East Carolina University.

\section{Financial Disclosure}

Funding for this project was provided by North Carolina House Bill 1043, 2020, COVID-19 Recovery Act.

\section{Competing Interests}

The authors have no competing interests. 


\section{References}

1. COVID Data Tracker. Centers for Disease Control and Prevention website. Accessed February 10, https://covid.cdc.gov/covid-data-tracker/\#datatracker-home

2. Mukherjee S. States are "diverging from CDC guidance," resulting in unequal vaccine rollout, experts say. Fortune. February 17, 2021. Accessed February 18, 2021. https://fortune.com/2021/02/17/covid-vaccine-cdc-guidelines-us-states-unequal-rolloutcoronavirus-vaccines-pfizer-biontech-moderna/

3. Appleby J. The state of vaccine supply: “Opaque.' Unpredictable. "Hard to pin down.” Kaiser Health News. February 5, 2021. Accessed February 18, 2021. https://khn.org/news/article/thestate-of-vaccine-supply-opaque-unpredictable-hard-to-pin-down/

4. Johnson A. Lack of health services and transportation impede access to vaccine in communities of color. Washington Post. Feb. 13, 2021. Accessed February 17, 2020. https://www.washingtonpost.com/health/2021/02/13/covid-racial-ethnic-disparities/

5. Khidir H, Molina M. Opinion: Moral Tragedy Looms in Early Chaos of U.S. COVID-19 Vaccine Distribution. National Public Radio. January 16, 2021. https://www.npr.org/sections/health-shots/2021/01/16/957236269/opinion-moral-tragedylooms-in-early-chaos-of-u-s-covid-19-vaccine-distribution

6. Engel-Smith LNC. Health News. In the rural race to distribute COVID vaccines, a piecemeal approach. February 10, 2021. https://www.northcarolinahealthnews.org/2021/02/10/in-therural-race-to-distribute-covid-vaccines-a-piecemeal-approach/

7. National Academies of Sciences, Engineering, and Medicine, 2020. Framework for Equitable Allocation of COVID-19 Vaccine. Washington, DC: The National Academies Press. https://doi.org/10.17226/25917

8. Flanagan BE, Gregory EW, Hallisey EJ, Heitger JL, Lewis B. 2011. A Social Vulnerability Index for Disaster Management. Journal of Homeland Security Management. 8(1), 3. https://doi.org/10.2202/1547-7355.1792

9. Duijzer LE, van Jaarsveld WL, Wallinga J, Dekker R. 2018. Dose-Optimal Vaccine Allocation over Multiple Populations. Prod Oper Manag. 27(1), 143-59. doi:https://doi.org/10.1111/poms.12788. PubMed

10. Flanagan BE, Hallisey EJ, Adams E, Lavery A. 2018. Measuring Community Vulnerability to Natural and Anthropogenic Hazards: The Centers for Disease Control and Prevention's Social Vulnerability Index. J Environ Health. 80(10), 34-36. PubMed

11. Chau PH, Gusmano MK, Cheng JO, Cheung SH, Woo J. 2014. Social vulnerability index for the older people-Hong Kong and New York City as examples. J Urban Health. 91(6), 104864. doi:https://doi.org/10.1007/s11524-014-9901-8. PubMed 
12. Horney JA, Nguyen M, Cooper J, Simon M, Ricchetti-Masterson K, et al. 2017. Accounting for vulnerable populations in rural hazard mitigation plans: results of a survey of emergency managers. J Emerg Manag. 11(3), 201-11. doi:https://doi.org/10.5055/jem.2013.0138. $\underline{\text { PubMed }}$

13. Bakkensen LA, Fox-Lent C, Read LK, Linkov I. 2017. Validating Resilience and Vulnerability Indices in the Context of Natural Disasters. Risk Anal. 37(5), 982-1004. Epub Aug 2016. doi:https://doi.org/10.1111/risa.12677. PubMed

14. North Carolina Interim COVID-19 Vaccination Plan. Executive Summary. October 16, 2020. Accessed on December 18, 2020. https:/files.nc.gov/covid/documents/NC-COVID-19Vaccine-Plan-with-Executive-Summary.pdf

15. Diabetes. Centers for Disease Control and Prevention. Accessed August 18, 2020. https://www.cdc.gov/diabetes/index.html?CDC_AA_refVal=https\%3A\%2F\%2Fwww.cdc.g ov\%2Fdiabetes\%2Fhome\%2Findex.html

16. CMS Medicare and Medicaid Chronic Conditions Data Warehouse. Accessed August 19, 2020. https://www2.ccwdata.org/web/guest/home/

17. Singh, G. Area Deprivation and Widening Inequalities in US Mortality, 1969-1998. American Journal of Public Health. July 203, Vol 93 no 7, pp 1137-1143.

18. Kind AJ, Jenks S, Brock J, Mengang Y, Bartels C, et al. 2014. Neighborhood Socio-economic Disadvantage and 30-day Rehospitalizations; an analysis of metadata. Ann Intern Med. 161(11), 765-74. PubMed https://doi.org/10.7326/M13-2946

19. Artiga S, Ndugga N, Pham O. Immigrant access to COVID-19 Vaccines: Key issues to consider. Kaiser Family Foundation. January 13, 2021. Accessed February 17, 2021. https://www.kff.org/racial-equity-and-health-policy/issue-brief/immigrant-access-to-covid19-vaccines-key-issues-to-consider/

20. COVID-19. Centers for Disease Control and Prevention. Accessed August 18, 2020. https://www.cdc.gov/coronavirus/2019-ncov/community/health-equity/race-ethnicity.html

21. Health Equity Considerations and Racial and Ethnic Minority Groups. Centers for Disease Control and Prevention. Accessed September 2020. https://www.cdc.gov/coronavirus/2019-ncov/community/health-equity/race-ethnicity.html

22. Behavioral Risk Factor Surveillance System. Centers for Disease Control and Prevention. Accessed August 18, 2020. https://www.cdc.gov/brfss/index.html

23. COVID Data Tracker. Centers for Disease Control and Prevention website. Accessed December 2, 2021. https://covid.cdc.gov/covid-data-tracker/\#datatracker-home 